\title{
Toxoplasma Gondii Infection among Pregnant Women in Guangdong Province, Subtropical Southern China
}

\author{
Chaohui Duan"\#, Zhangyong Ning ${ }^{2 * \#}$, Wenbo Hao ${ }^{3 \#}$, Xiaohong Luo ${ }^{1}$, Jianping Tan ${ }^{4}$, Ling Luo ${ }^{1}$, Yingming He ${ }^{5}$, Ying $\mathrm{Xu}^{1}$, Jing Shao ${ }^{6}$ and \\ Shuhong Luo ${ }^{3 *}$
}

${ }^{1}$ Laboratory of Clinical Immunology, the Sun Yat-Sen Memorial hospital, Sun Yat-Sen University, 107 W. Yanjiang Road, Guangzhou 510120, People's Republic of China ${ }^{2}$ College of Veterinary Medicine, South China Agricultural University, Guangzhou 510642, People's Republic of China

3Institute of Antibody Engineering, School of Biotechnology, Southern Medical University, 1838 N. Guangzhou Avenue, Guangzhou, 510515, People's Republic of China ${ }^{4}$ Department of Obstetric and Gynecology, the Sun Yat-Sen Memorial Hospital, Sun Yat-Sen University, 107 W. Yanjiang Road, Guangzhou 510120, Guangzhou 510120, People's Republic of China

${ }^{5}$ Laboratory of Department of Obstetric and Gynecology, the Sun Yat-Sen Memorial Hospital, Sun Yat-Sen University, 107 W. Yanjiang Road, Guangzhou 510120, People's Republic of China

${ }^{6}$ Lin Bai-xin research center of medicine memorial hospital, Sun Yat-sen University, Sun Yat-Sen University, 107 W. Yanjiang Road, Guangzhou 510120, Guangdong, People's Republic of China

"Authors have contributed equally

\begin{abstract}
Little is known about the prevalence of infection by $T$. gondii in pregnant women in subtropical Southern China. The seroprevalence of $T$. gondii infection and associated risk factors were investigated in Guangdong province between April 2009 and August 2011. 5006 pregnant women participated in this study. Participants answered survey questions and blood samples were collected from these pregnant women. IgM and IgG antibodies were detected with Enzyme-Linked Immunoadsorbent Assay (ELISA). The odds ratio (OR) and 95\% confidence interval $(95 \% \mathrm{CI})$ between anti-lgM, IgG antibodies and relative risk factors were calculated using an association analysis based on unconditional logistic regression. Totally, $0.46 \%$ and $7.01 \%$ of the pregnant women were found to be positive for $T$. gondii IgM and IgG antibodies, respectively. Risk factors for Toxoplasma gondii infection in women were: contact with cats [odds ratio (OR) 4.99], consumption of raw or under-cooked wild and domestic animals (rats, rabbits and cats) or pork products (OR 4.08) and two administrative regions of Shaoguan and Zhanjiang with habits of eating non-cooked meat (OR 3.93 and 2.58). No significant relations were observed between anti-Toxoplasma IgM and IgG antibodies and unwashed raw vegetables or fruits, educational level and different age group. This is the first report of seroprevalence and risk factors for $T$. gondii infection among pregnant women in subtropical southern China. This study provides a basis for the design of successful preventive measures against $T$.gondii infection in pregnant women.
\end{abstract}

Keywords: Toxoplasma gondii; Pregnant women; Seroprevalence; Risk factors; ELISA; Subtropical southern

\section{Introduction}

Toxoplasmosis, a zoonotic disease of humans and most animals with a worldwide distribution, is caused by the opportunistic intercellular parasite T. gondii $[1,2]$. The main routes of transmission in humans are ingestion of tissue cysts in undercooked or oocyst contaminated food and through placental transmission to the fetus [3]. When the infection occurs in pregnant women, it can cause severe disease symptomatology including toxoplasmic encephalitis, blindness, fetal abnormalities, abortion and even stillbirth [4,5]. Previous reports showed that $39 \%$ of fetuses showed subclinical or clinical infection when the pregnant women acquired the infection for the first time [6]. Incidence of congenital toxoplasmosis ranges from $0.01-1.1 \%$ live births [4].

The seroprevalence of exposure to T. gondii is influenced by many factors such as climate and environmental conditions, food habit and culture [1]. The reported infection rate in pregnant women varies between countries as well as different areas within the same country [7]. Higher infection rates have been reported in the countries of Central and South America, Africa and Asia [3, 8, 9] compared to Northern Europe and the United States [9-11]. For Asian countries, the prevalence in India, Malaysia and Nepal are higher (41.8-51.4\%) than that in Korea $(0.8 \%)$, Vietnam $(11.2 \%)$ and China $(10.6)[8,12]$. Many researches have shown that pregnant women with positive IgG but negative IgM are latently infected, and only with a positive IgM titer were they considered to have an active infection $[8,9,12]$. Within China, because of the different environmental and food habits, there is considerable variation in infection rates among pregnant women in the different areas and provinces [13]. Specifically, there is very limited epidemiological information on $T$. gondii infection among pregnant women in Guangdong province. Guangdong faces the South China Sea to the south and is the most populous province in China, with a popu-

\begin{tabular}{|c|c|c|c|c|}
\hline \multirow{2}{*}{} & \multirow{2}{*}{} & \multicolumn{2}{|c|}{ IgM } & Total \\
\cline { 2 - 5 } & + & 20 & 331 & $351(7.01 \%)$ \\
\hline \multirow{2}{*}{$\lg \mathbf{*}$} & - & 3 & 4652 & 4655 \\
\hline \multirow{2}{*}{} & Total & $23(0.46 \%)$ & 4983 & 5006 \\
\hline
\end{tabular}

$\chi^{2}>100.00, \mathrm{p}<0.001$

Table 1: The IgM and the IgG of T.gondii infection in pregnant women.

*Corresponding authors: Shuhong Luo, Institute of Antibody Engineering, School of Biotechnology, Southern Medical University, 1838 N. Guangzhou Avenue, Guangzhou, 510515, China, E-mail: shluo815@yaoo.com

Zhangyong Ning, College of Veterinary Medicine, South China Agricultural University, Guangzhou 510642, People's Republic of China,E-mail: ningzhyong@ scau.edu.cn

Received February 11, 2012; Accepted April 19, 2012; Published April 20, 2012

Citation: Duan C, Ning Z, Hao W, Luo X, Tan J, et al. (2012) Toxoplasma Gondii Infection among Pregnant Women in Guangdong Province, Subtropical Southern China. J Med Microb Diagn 1:107. doi:10.4172/2161-0703.1000107

Copyright: (c) 2012 Duan C, et al. This is an open-access article distributed under the terms of the Creative Commons Attribution License, which permits unrestricted use, distribution, and reproduction in any medium, provided the original author and source are credited. 
Citation: Duan C, Ning Z, Hao W, Luo X, Tan J, et al. (2012) Toxoplasma Gondii Infection among Pregnant Women in Guangdong Province, Subtropical Southern China. J Med Microb Diagn 1:107. doi:10.4172/2161-0703.1000107

Page 2 of 4

lation of approximately 110 million people, including approximately 30 million migrants. The purpose of this study was to determine the prevalence of $T$. gondii infection and evaluate associated risk factors of T.gondii infection among pregnant women in Guangdong province, subtropical southern China.

\section{Methods}

\section{Study population}

This study was conducted in Guangdong province $\left(20^{\circ} 13^{\prime}-25^{\circ} 31^{\prime}\right.$ $\mathrm{N}, 109^{\circ} 39^{\prime}-117^{\circ} 19^{\prime} \mathrm{E}$ ), which extends about $179,800 \mathrm{~km} 2$ in southern China. The climate of the Guangdong is subtropical; the average annual temperature and precipitation are $23.3^{\prime}$ and $1300-1500 \mathrm{~mm}$ respectively (http://www.gd.gov.cn/gdgk/sqgm/zrdl).
Five thousand and six pregnant women who reported for antenatal care in Sun Yet-sen memorial hospital for the first or second time from April, 2009 to August, 2011 gave verbal consent for the detection of Toxoplasma gondii. An individual questionnaire was completed for each woman. The pregnant women were from different districts across Guangdong province (Table 1) and ranged in age from 16-46 years old (Table 2). Inclusion criteria for the study subjects were: age, home town, residency in rural or urban area, type of housing (apartment or house), knowledge of toxoplasmosis, consumption of unwashed raw vegetables or fruit, meat consumption (beef, goat, lamb, pork, poultry and/or rabbit) and consumption of raw or undercooked meat.

\section{Ethical aspects}

This study was approved by both the ethics committee of Sun Yat-

\begin{tabular}{|c|c|c|c|c|c|c|c|c|c|c|}
\hline Districts & $\begin{array}{c}\text { Pregnant } \\
\text { women tested } \\
(n)\end{array}$ & $\begin{array}{c}\text { Relative } \\
\text { distribution } \\
(\%)\end{array}$ & $\begin{array}{c}\text { Ig M Seroposi- } \\
\text { tive (n) }\end{array}$ & $\begin{array}{c}\text { IgM Seropreva- } \\
\text { lence } \\
(\%)\end{array}$ & P-value & $95 \% \mathrm{Cl}$ & $\begin{array}{l}\text { Ig G Seroposi- } \\
\text { tive (n) }\end{array}$ & $\begin{array}{c}\text { IgG Seropreva- } \\
\text { lence } \\
(\%)\end{array}$ & P-value & $95 \% \mathrm{Cl}$ \\
\hline Guangzhou & 3713 & 74.17 & 15 & 0.40 & 0.356 & $3.08-6.18$ & 231 & 6.22 & 0.388 & $48.21-78.72$ \\
\hline Shenzhen & 249 & 4.98 & 1 & 0.40 & 0.335 & $3.02-6.05$ & 16 & 6.42 & 0.395 & $46.03-72.43$ \\
\hline Huizhou & 157 & 3.14 & 1 & 0.64 & 0.067 & $4.46-8.95$ & 11 & 7.01 & 0.253 & $49.76-80.29$ \\
\hline Zhuhai & 226 & 4.52 & 1 & 0.44 & 0.393 & $3.13-6.31$ & 17 & 7.52 & 0.362 & $51.36-81.81$ \\
\hline Foshan & 181 & 3.62 & 1 & 0.55 & 0.112 & $3.75-8.39$ & 13 & 7.18 & 0.177 & $49.78-79.08$ \\
\hline Shaoguan & 219 & 4.37 & 2 & 0.91 & $0.00091^{* *}$ & $6.39-15.52$ & 30 & 14.16 & $0.00102^{* *}$ & $83.27-91.58$ \\
\hline Zhanjiang & 258 & 5.15 & 2 & 0.78 & $0.025^{\star}$ & $5.43-12.86$ & 33 & 12.79 & $0.0213^{*}$ & $80.53-90.22$ \\
\hline Total & 5006 & 100.00 & 23 & 0.46 & 0.168 & $3.26-8.66$ & 351 & 7.01 & 0.139 & 49.06-80.01 \\
\hline
\end{tabular}

*: Significantly higher than in other districts $(P<0.05)$;

**: Significantly higher than in all the other districts $(P<0.01)$

Table2: Seroprevalence of T. gondii infection among pregnant women in different districts in Guangdong province.

\begin{tabular}{|c|c|c|c|c|c|c|c|c|c|c|}
\hline $\begin{array}{l}\text { Age } \\
\text { group } \\
\text { (years) }\end{array}$ & $\begin{array}{l}\text { Pregnant } \\
\text { women } \\
\text { tested } \\
\text { (n) }\end{array}$ & $\begin{array}{l}\text { Relative } \\
\text { distribu- } \\
\text { tion } \\
(\%)\end{array}$ & $\begin{array}{c}\text { Ig M Seroposi- } \\
\text { tive (n) }\end{array}$ & $\begin{array}{l}\text { IgM Serop- } \\
\text { revalence } \\
(\%)\end{array}$ & P-value & $95 \% \mathrm{Cl}$ & $\begin{array}{c}\text { Ig G Seroposi- } \\
\text { tive (n) }\end{array}$ & $\begin{array}{l}\text { Ig G Serop- } \\
\text { revalence } \\
(\%)\end{array}$ & P-value & $95 \% \mathrm{Cl}$ \\
\hline $16-20$ & 95 & 1.90 & 0 & 0.00 & - & - & 3 & 3.12 & $0.023^{*}$ & $20.01-31.59$ \\
\hline $21-25$ & 396 & 7.91 & 1 & 0.25 & 0.053 & $1.72-4.16$ & 15 & 3.79 & $0.039^{*}$ & $21.38-32.79$ \\
\hline $26-30$ & 1926 & 38.47 & 9 & 0.47 & 0.392 & $3.13-8.22$ & 136 & 7.06 & 0.576 & $49.85-81.21$ \\
\hline $31-35$ & 1652 & 33.00 & 8 & 0.48 & 0.351 & $3.41-8.58$ & 131 & 7.93 & 0.257 & $52.30-81.31$ \\
\hline $36-40$ & 751 & 15.00 & 4 & 0.53 & 0.176 & $3.65-8.99$ & 57 & 7.59 & 0.295 & $51.33-80.36$ \\
\hline $40-46$ & 186 & 3.72 & 1 & 0.54 & 0.139 & $3.77-9.37$ & 9 & 4.84 & 0.062 & $27.55-38.09$ \\
\hline Total & 5006 & 100.00 & 23 & 0.55 & 0.373 & $3.21-7.35$ & 351 & 7.01 & 0.418 & $42.58-79.73$ \\
\hline
\end{tabular}

*: Significantly higher than in other districts $(\mathrm{P}<0.05)$;

Table 3: Seroprevalence of T. gondii infection in pregnant women at different age groups.

\begin{tabular}{|c|c|c|c|c|c|c|c|c|c|c|}
\hline Characteristic & $\begin{array}{l}\text { Pregnant } \\
\text { women } \\
\text { tested } \\
\text { (n) }\end{array}$ & $\begin{array}{c}\text { Relative } \\
\text { distribu- } \\
\text { tion } \\
(\%)\end{array}$ & $\begin{array}{l}\text { Ig M Sero- } \\
\text { positive (n) }\end{array}$ & $\begin{array}{c}\text { Ig M Serop- } \\
\text { revalence } \\
(\%)\end{array}$ & P-value & $95 \% \mathrm{Cl}$ & $\begin{array}{l}\text { Ig G Sero- } \\
\text { positive (n) }\end{array}$ & $\begin{array}{c}\text { Ig G Serop- } \\
\text { revalence } \\
(\%)\end{array}$ & P-value & $95 \% \mathrm{Cl}$ \\
\hline \multicolumn{11}{|c|}{ Degree of meat cooking } \\
\hline Well done & 1113 & 22.23 & 3 & 0.27 & \multirow[t]{2}{*}{$P=0.0029^{* *}$} & $1.78-4.13$ & 46 & 4.13 & \multirow[t]{2}{*}{$\mathrm{P}=0.0041^{\star *}$} & 26.66-39.09 \\
\hline Raw or undercook & 3893 & 77.77 & 20 & 0.51 & & $3.23-7.82$ & 305 & 7.83 & & $51.78-81.52$ \\
\hline \multicolumn{11}{|l|}{ Contact with the cat } \\
\hline Yes & 2719 & 54.31 & 18 & 0.66 & \multirow[t]{2}{*}{$P=0.00073^{* *}$} & $4.23-8.66$ & 289 & 10.63 & \multirow{2}{*}{$P=0.00030^{* *}$} & 79.91-88.36 \\
\hline No & 2287 & 45.69 & 5 & 0.22 & & $1.51-3.61$ & 62 & 2.71 & & $15.03-21.38$ \\
\hline \multicolumn{11}{|c|}{$\begin{array}{l}\text { Unwashed raw vegeta- } \\
\text { bles or fruits }\end{array}$} \\
\hline Yes & 817 & 16.32 & 4 & 0.49 & \multirow[t]{2}{*}{$P=0.267$} & $3.18-7.80$ & 61 & 7.47 & \multirow[t]{2}{*}{$P=0.598$} & $50.13-81.05$ \\
\hline No & 4189 & 83.68 & 19 & 0.45 & & $3.13-7.72$ & 290 & 6.92 & & 48.53-79.71 \\
\hline \multicolumn{11}{|l|}{ Education level } \\
\hline Educational & 589 & 11.76 & 3 & 0.51 & \multirow[t]{2}{*}{$P=0.203$} & 2.93-8.02 & 52 & 8.83 & \multirow[t]{2}{*}{$P=0.097$} & $52.75-82.67$ \\
\hline No Educational & 4417 & 88.24 & 20 & 0.45 & & $3.20-7.62$ & 299 & 6.77 & & $47.16-78.05$ \\
\hline
\end{tabular}

**: Significantly higher than in all the other districts $(P<0.01)$

Table 4: Risk factors associated with T. gondii infection in pregnant women in Guangdong province. 
Citation: Duan C, Ning Z, Hao W, Luo X, Tan J, et al. (2012) Toxoplasma Gondii Infection among Pregnant Women in Guangdong Province, Subtropical Southern China. J Med Microb Diagn 1:107. doi:10.4172/2161-0703.1000107

Page 3 of 4

\begin{tabular}{|c|c|c|c|c|}
\hline & $\begin{array}{c}\text { IgG Seroprevalence } \\
(\mathbf{\%})\end{array}$ & OR & 95\% Cl & IgG Seroprevalence \\
(\%)
\end{tabular}

Table 5: Identification of risk factors for T.gondii infection in pregnant women by multiple logistic regression analysis.

sen University and by the medical boards of Sun Yet-sen memorial hospital. The purpose and procedures of this investigation were explained to all participants, and informed consent was obtained from all the women studied.

\section{Serological analysis for T.gondii antibodies}

Blood samples were taken from the women under aseptic conditions; the sera were separated and stored at $-80 \mathrm{oC}$ until further testing. Serum samples were tested for IgM and IgG against T.gondii using enzyme-linked immunoadsorbent assay (Toxoplasma gondii IgM and IgG $\mu$-capture Elisa assay; Hamburg, German). Serological tests were performed according to the manufacture's instruction at the biological laboratory of Sun Yet-sen memorial hospital.

\section{Statistical analysis}

All data were analyzed with SPSS 13.0 Data Editor (SPSS Inc, Chicago, IL, USA). Bivariate and multivariate analyses were used to assess all the different districts, age differences and risk factors associated with T. gondii infection. If the $\mathrm{P}$ value $<0.3$ in the bivariated analysis, the variable was included into the multivariate analysis. $95 \%$ confidence intervals (CIs) and odds ratios (ORs) were calculated by multivariate analysis using a multiple, unconditional logistic regression model. The differences were considered to be statistically significant when the $p$ value obtained was less than 0.05 .

\section{Results}

\section{T. gondii infection in pregnant women in different districts in Guangdong province}

Total twenty-three $(0.46 \%)$ and $351(7.01 \%)$ of 5006 pregnant women were found to be positive for T. gondii IgM and IgG antibodies, respectively (Table 1). Estimated seroprevalence of toxoplasma IgM and IgG among the districts ranged from $0.4 \%$ to 0.91 and $6.22 \%$ $14.16 \%$ respectively. Two districts, Shaoguan $(0.91 \%, \mathrm{p}=0.00091$ for IgM and $14.16 \%, P=0.00102$ for IgG) and Zhanjiang $(0.78 \%, p=0.025$ for IgM and $12.79 \%, p=0.0213$ for IgG) have significantly higher infection rates compared to other districts (Table 2).

\section{$T$. gondii infection in pregnant women in different age groups}

The pregnant women tested were divided into 5 age groups: under 20 years, $21-25$ years, 26-30 years, $31-35$ years, $36-40$ years and over 40 years. The distribution and the positive rates are shown in Table 3. Although the active infection positive rate varied in different age groups, the IgM positive rate ranged from $0 \%(<20$ years) to $0.54 \%$ ( $>40$ years) and IgG positive rate ranged from $3.12 \%$ ( $<20$ years) to $7.93 \%$ (31-35 years). No statistically significant differences were observed among all age groups (Table $3, \mathrm{P}>0.05$ ).

\section{Risk factors associated with $T$. gondii infection in pregnant women}

Risk factors related to eating preferences and hygienic habits are given in (Table 4). In pair wise comparisons, no statistically significant differences were found between the groups with and without a formal education, between the groups who consumed unwashed raw vegetables or fruits and those who washed them. However, significant differences $(p<0.01)$ were detected between the group not consuming raw or under-cooked meat and those eating raw or under-cooked meat (3.237.82, $\mathrm{p}=0.0029$ for IgM and 51.78-81.52, $\mathrm{p}=0.0041$ for $\operatorname{IgG}$ ); all possible risk factors were explored, degree of meat cooking, between the groups having no contact with cats (1.51-3.61 for IgM and 79.91-88.36 for IgG) and contact or owning cats (4.23-10.66;for IgM and 15.03-21.38,).

The analysis of odds ratios (ORs) and 95\% confidence intervals (95\% CIs) between anti-IgM antibodies and relative risk factors are given in Table 5. Risk factors for T.gondii infection in decreasing order were: contact cats (OR 4.99 for IgM and OR 6.57 for IgG), consumption of raw or under-cooked meat (OR 4.08 for IgM and OR 7.83 for IgG) and geographic locations (Shaoguan, OR 3.93 and Zhangjiang, OR 2.58).

\section{Discussion}

In China, policy of healthy pregnancy had strengthened to execute for women of childbearing age to improve the quality of reproduction for several years. Most pregnant women now voluntarily go to the hospital to obtain prenatal care. If a woman becomes actively infected with T.gondii during pregnacy there is a high probability that there will be deleterious effects on the development of the fetus including abortion and stillbirth [14-17]. Almost all of the public hospitals in China, screen for the IgM and IgG of T. gondii at early pregnancy. The emergence of IgM and IgG positive against $T$. gondii showed is a strong indicator of active infection and immediate measures should be taken to assure $r$ treatment.

The $0.46 \%$ and $7.01 \%$ of T. gondii IgM and IgG psoitivity in pregnant women from Guangdong province, respectively, is much lower than Tirana and vlore $1.3 \%$ of $\operatorname{IgM}$ and $48.6 \%$ of $\operatorname{IgG}$ positive in $\mathrm{Al}-$ bania [18], $4.1 \%$ of IgM and $29.4 \%$ of IgG positive in Kosovo [19], $1.22 \%$ of IgM and $49.2 \%$ of IgG positive in brazil [20], 3,26\% of IgM and $53.03 \%$ of IgG positivein southern brazil [21], 2.8\% of IgM and $45.8 \%$ of IgG positive in Cali, Colombia, South America [3]. Our result is much higher than the reported $0 \%$ of IgM and $10.6 \%$ for IgG positive from other cities in China, for example a $0 \%$ active infection in pregnant women in Changchun [8], but is much lower than 6.6\% of IgM in Wuhan [22] and $27.2 \%$ of IgM positive in Weifang [23]. 
Citation: Duan C, Ning Z, Hao W, Luo X, Tan J, et al. (2012) Toxoplasma Gondii Infection among Pregnant Women in Guangdong Province, Subtropical Southern China. J Med Microb Diagn 1:107. doi:10.4172/2161-0703.1000107

Page 4 of 4

The potential risk for the pregnant women to become infected with T. gondii in our investigation showed that contact with cats, and consumption of undercooked or raw meat to be the most significant risk factors in Guangdong province consistent with previous reports [7, 8, 9, 10, 24]. Evidence that companion animals such as cats are hosts of $T$. gondii had been previously confirmed $[1,2,6,8,10,12,18,20$, $24,25,26]$. Thus, pregnant women in contact with these infected pets will naturally be at greater risk of acquiring active infection. The study confirmed that consumption of undercooked or raw meat and contact with the cats were the greater risk factors for the pregnant women studied. The subjects from Shaoguan and Zhanjiang districts had increased seroprevalence because people living in those areas have habits of both consumption of undercooked or raw meat of cats and regular contact with cats.

In summary, the present investigation revealed that $0.46 \%$ of IgM and $7.01 \%$ of pregnant women in subtropical southern China were seropositive for IgM and IgG against T. gondii.

It is interesting to note that contact with cats and consumption of uncooked or under-cooked meat were a significant risk factors for pregnant women. This is the first report of seroprevalence and risk factors for T. gondii infection among pregnant women in subtropical southern China. This study provides a basis for the design of successful preventive measures against T.gondii infection in pregnant women.

\section{Acknowledgments}

This work was supported by the start grants from Guangdong province and Southern Medical University (to Shuhong Luo) and by the grant (No. 8151008901000035 and No. 2010A0304 00006) from the Natural Science Foundation of Guangdong and Science and Technology Plan Projects of Guangdong.

\section{References}

1. Dubey JP. Toxoplasmosis of Animals and Humans. CRC Press Inc. Second edition. Boca Raton, New York; 1-313.

2. Webster JP (2010) Review of Toxoplasmosis of Animals and Humans. Parasit Vectors 3:112.

3. Rosso F, Les JT, Agudelo A, Villalobos C, Chaves JA, et al. (2008) Prevalence of infection with Toxoplasma gondii among pregnant women in Cali, Colombia, South America. Am J Trop Med Hyg 78: 504-508.

4. Montoya JG, Liesenfeld O (2004) Toxoplasmosis. Lancet 363: 1965-1976.

5. Cook AJ, Gilbert RE, Buffolano W, Zufferey J, Petersen E, et al. (2000) Sources of toxoplasma infection in pregnant women: European multicentre case-control study. European Research Network on Congenital Toxoplasmosis. BMJ 321: 142-147.

6. Dunn D, Wallon M, Peyron F, Petersen E, Peckham C, et al. (1999) Mother-tochild transmission of toxoplasmosis: risk estimates for clinical counselling. Lancet 353: 1829-1833.

7. Tenter AM, Heckeroth AR, Weiss LM (2000) Toxoplasma gondii: from animals to humans. Int J Parasitol 30: 1217-1258.

8. Liu Q, Wei F, Gao S, Jiang L, Lian H, et al. (2009) Toxoplasma gondii infection in pregnant women in China. Trans R Soc Trop Med Hyg 103: 162-166.

9. Sroka S, Bartelheimer N, Winter A, Heukelbach J, Ariza L, et al. (2010) Prevalence and risk factors of toxoplasmosis among pregnant women in Fortaleza, Northeastern Brazil. Am J Trop Med Hyg 83: 528-533.

10. Nash JQ, Chissel S, Jones J, Warburton F, Verlander NQ (2005) Risk factors for toxoplasmosis in pregnant women in Kent, United Kingdom. Epidemiol Infect 133: $475-483$.

11. Dubey JP, Jones JL (2008) Toxoplasma gondii infection in humans and animals in the United States. Int J Parasitol 38: 1257-1278.

12. Alvarado-Esquivel C, Sifuentes-Alvarez A, Narro-Duarte SG, Estrada-Martínez S, Díaz-García JH, et al. (2006) Seroepidemiology of Toxoplasma gondii infection in pregnant women in a public hospital in northern Mexico. BMC Infect Dis 13: 113.
13. Xu LQ, Chen YD, Sun FH, Cai L, Fang YY, et al. (2005) A national survey on current status of the important parasitic diseases in human population. China $J$ Parasitol parasite Dis 23: 332-339.

14. ttp://www.fabcats.org/cat_group/policy_statements/toxo.html

15. Jones J, Lopez A, Wilson M (2003) Congenital toxoplasmosis. Am Fam Physician 67: 2131-2138.

16. Jenum PA, Stray-Pedersen B, Melby KK, Kapperud G, Whitelaw A, et al. (1998) Incidence of Toxoplasma gondii infection in 35,940 pregnant women in Norway and pregnancy outcome for infected women. J Clin Microbiol 36: 2900-2906.

17. Jones JL, Lopez A, Wilson M, Schulkin J, Gibbs R (2001) Congenital toxoplasmosis: a review. Obstet Gynecol Surv 56: 296-305.

18. Maggi P, Volpe A, Carito V, Schinaia N, Bino S, et al. (2009) Surveillance of toxoplasmosis in pregnant women in Albania. New Microbiol 32: 89-92.

19. Dentico P, VolpeA, Putoto G, Ramadani N, Bertinato L, et al. (2011) Toxoplasmosis in Kosovo pregnant women. New Microbiol 34: 203-207.

20. Lopes FM, Mitsuka-Breganó R, Gonçalves DD, Freire RL, Karigyo CJ, et al. (2009) Factors associated with seropositivity for anti-Toxoplasma gondii antibodies in pregnant women of Londrina, Paraná, Brazil. Mem Inst Oswaldo Cruz 104: 378-382.

21. Vaz RS, Thomaz-Soccol V, Sumikawa E, Guimarães AT (2010) Serological prevalence of Toxoplasma gondii antibodies in pregnant women from Southern Brazil. Parasitol Res 106: 661-665.

22. Xu SQ, Guo H, Liu GY (1996) Anti- Toxoplasma gondii IgM antibodies detection in pregnant women. Wuhanyixuezazhi 20: 64.

23. Zhang J, Zhou JM, Liang SJ (2003) Detection and analysis of Toxoplasma gondii antibodies infection of childbearing women. Weifangyixueyuanxuebao 25: 239.

24. Jones JL, Kruszon-Moran D, Wilson M, McQuillan G, Navin T, et al. (2001) Toxoplasma gondii infection in the United States: seroprevalence and risk factors. Am J Epidemiol 154: 357-365.

25. Jones JL, Krueger A, Schulkin J, Schantz PM (2010) Toxoplasmosis prevention and testing in pregnancy, survey of obstetrician-gynaecologists. Zoonoses Public Health 57: 27-33

26. Edelhofer R, Prossinger H (2010) Infection with Toxoplasma gondii during pregnancy: seroepidemiological studies in Austria. Zoonoses Public Health 57 18-26. 